ISSN: $1130-3743$

\title{
LECTURA DE LA EXPERIENCIA DEL MIEDO: MUJERES LEYENDO $^{1}$
}

\author{
Fear experience reading: women reading
}

\section{Lecture de l'expérience de la peur: des femmes qui lisent}

\author{
Sofía VALdIVIESO GÁMEZ \\ Universidad de las Palmas de Gran Canaria. Facultad de Formación del Profesorado. \\ Departamento de Educación. C/ Juana de Arco, 1. 35004 Las Palmas de Gran \\ Canaria.Correo-e: svaldivielso@dedu.ulpgc.es
}

Fecha de recepción: enero de 2006

Fecha de aceptación definitiva: abril de 2006

BIBLID [(1130-3743) 18, 2006, 175-200]

RESUMEN

Partiendo de las ideas que el paradigma patriarcal ha utilizado en la construcción de las identidades masculinas y femeninas, los cambios vividos por las mujeres en el último siglo y los testimonios sobre los miedos experimentados por más de 25 mujeres de distintas edades y nacionalidades en las diferentes etapas de sus ciclos vitales, la autora construye un relato sobre qué les da miedo a las mujeres, cómo lo viven y cómo lo resuelven. Todo ello sustentado en la hipótesis de que si el patriarcado como organización social es una constante cultural, los miedos que experimentan las mujeres en el proceso de construirse como tales también lo son. Concluye que el camino a seguir pasa necesariamente por la integración de lo femenino consciente, tanto en hombres como en mujeres, como paso previo para la construcción de una realidad de iguales diferentes, que nos permita descubrir la dimensión masculina y femenina en cada uno de nosotros.

1. Este artículo no hubiera sido posible sin la colaboración desinteresada de las mujeres que me han regalado sus testimonios, a todas ellas les doy las gracias. 
Palabras clave: mujeres, emociones, miedo, ciclo vital, patriarcado, sistemas de
género.

SUMMARY

Starting from the assumptions the patriarchal paradigm has used in the construction of male and female identity, the changes experienced by women in the last century and the statements about fear undergone by more than twenty-five women from different ages and nationalities through their own life cycle, the author gives us an account on what women fear and how they live and overcome it. These ideas are based on the hypothesis that if patriarchy as a social organization is a cultural constant, the fears experienced by women in the process of constructing themselves as such are also constant. She concludes that the only course to follow is necessarily a way where feminine consciousness must be integrated, both in men and women, as a previous step in the construction of a reality based on equals, though, at the same time, different. This would allow us to discover the masculine and feminine dimension in all of us.

Key words: women, emotions, fear, life cycle, patriarchy, gender systems.

\section{SOMMAIRE}

Nous présentons ici un rapport sur ce qui fait peur aux femmes, comment elles ressentent cette peur et comment elles essaient de la combattre, tout en prenant comme point de départ les idées utilisées par la pensée partriarcale pour la construction des identités masculine et féminine, les changements subis par les femmes pendant le siècle dernier et les témoignages de plus de 25 femmes d'âge et nationalité divers. Une hypothèse sous-tend notre travail: si le partriarcat, comme type d'organisation sociale, constitue une constante culturelle, les peurs subies par les femmes dans leur processus de construction en tant que telles en constituent une également. Comme solution possible, et en guise de conclusion, nous proposons d'intégrer le féminin conscient, tant chez les hommes que chez le femmes, comme passage préalable à la construction d'une réalité d'égalité différenciée, qui nous permettrait de découvrir les dimensions masculine et féminine qui existent chez nous tous et toutes.

Mots clef: femmes, émotions, peur, cycle vital, patriarcat, système du genre.

\section{INTRODUCCIÓN Y ALGUNAS EXPLICACIONES PREVIAS}

El tiempo transcurrido entre la aceptación de escribir un artículo que hablara sobre la emocionalidad en las mujeres y lo que el lector o lectora tiene ahora en sus manos, ha sido de casi un año. Mi primera reacción fue pensar que un buen artículo podría estructurarlo en tres partes. En una primera parte hablaría de los avances científicos en relación a la fisiología de las emociones (Aguado, 2005; 
LeDoux, 1999) al mismo tiempo que presentaría someramente los nuevos paradigmas emergentes (Wilber, 1996; Morin, 1998; Maturana, 2003). A continuación expondría algunas explicaciones sobre los tres cerebros y su interrelación en una compleja malla de interacciones (Wilber, 2001; Servan, 2003) y concluiría el apartado con los avances en relación con la función de cada uno de los hemisferios cerebrales, en el que el derecho rige la visión holística, la creatividad y la emocionalidad, aspectos que se relacionan con lo femenino; y el izquierdo, la visión focal, la lógica y la racionalidad, relacionados con lo masculino (Shlain, 2000; Servan, 2003).

En un segundo apartado analizaría las aportaciones del feminismo a la deconstrucción del sistema patriarcal (Salomon, 2003; Zweig, 2001; Amorós, 1997; Lagarde, 1996; Valcárcel, 1993; Gilligan, 1982) y cómo el hecho de que las mujeres hayan ocupado un espacio que históricamente había sido sólo de hombres ha producido lo que algunos autores llaman "la revolución silenciosa de las mujeres" (Castells, 1997; Giddens, 1991). En menos de un siglo hemos cambiado muchas cosas en nuestras vidas, estamos consiguiendo hacernos visibles en muchos escenarios, enseñando a las nuevas generaciones que la realidad no debe seguir siendo analizada desde una perspectiva dicotómica (Morin, 2001, 1984; Wilber, 1996) sujeto/ objeto; masculino/femenino; racional/emocional; público/privado; etc. Esta perspectiva ha producido una visión chata del mundo en la que sólo se tienen en cuenta las superficies y se olvidan las profundidades. Los nuevos acercamientos nos dicen que no somos sólo una cosa u otra. Por el contrario, somos las dos cosas al mismo tiempo, simultáneamente. En un segundo punto de este apartado, pensé que podría reflexionar sobre cómo estos cambios han afectado y están afectando a los hombres en la construcción de su masculinidad (Lomas, 2003; Salomon, 2005). Concluiría este apartado apostando por una construcción paritaria de la realidad, tanto en el espacio público como en el privado pues como bien recoge la sabiduría popular "la mitad del cielo lo sostienen las mujeres".

En el tercer y último apartado presentaría algunas reflexiones de los límites de una visión chata del mundo. De cómo esa visión ha producido seres incompletos, cojos, gigantes intelectuales pero enanos emocionales. Luego pasaría a reflexionar sobre la escuela actual, de cómo es una institución pensada para el siglo XIX, y lógicamente hay que ajustarla al siglo XXI. ¿Qué enseñar en un mundo globalizado? ¿Cómo reconstruir al hombre y a la mujer fragmentado/da? ¿Cómo favorecer el nacimiento del ser humano integrado? ¿Qué significará ser un hombre o una mujer en el siglo XXI o en el siguiente? (Naranjo, 2004; Morin, 2001) y concluiría con una invitación a seguir reflexionando.

Le mandé una primera aproximación a un amigo. Su contestación me sorprende y me anima. Lo que le había mandado le parecía demasiado obvio y me propone que lo que debería hacer era una lectura femenina del mundo de las emociones.

En un principio esta respuesta me pareció estupenda y así se lo hice saber. No hacía otra cosa que darle vueltas al tema de las emociones y, al mismo tiempo que pensaba, una emoción fue tomando la escena. Una emoción muy femenina, relacionada con mis inseguridades a atreverme a decir lo que pienso y lo que siento, sin tener 
en cuenta si se ajusta o no a la norma social y académica, pues ellas han sido pensadas y legitimadas por el otro masculino y nosotras, si queremos el reconocimiento social y académico, no tenemos más remedio que cumplirla porque está tan dentro de nosotras que hemos llegado a pensar que es objetiva y neutra, que las cosas son como deben ser. Sin embargo pensar sobre esto me alteraba porque escribir sobre las emociones desde el lenguaje racional me metía en un callejón sin salida y además me producía mucho miedo. Así se lo comenté a mi amigo y me sugirió reflexionar sobre esa emoción. Sobre el miedo de las mujeres.

Abandoné el camino anterior y comencé a transitar por otras rutas relacionadas con el miedo. Centré mis lecturas en esta emoción. El miedo es una de las emociones más estudiadas y probablemente la más antigua. Una respuesta adaptativa a las situaciones que los seres vivos se representan como riesgo, una memoria biológica donde las especies mantienen el recuerdo de las situaciones en las que sus genes perdieron oportunidad (Aguado, 2005; LeDoux, 1999). Pero los seres humanos no sólo somos seres biológicos, también somos psicológicos, culturales, sociales e históricos por lo que nuestras representaciones del riesgo van más allá de la biología y atraviesan todas las otras dimensiones. Los relatos en torno al miedo son muy variados y aunque desde perspectivas muy distintas, ponen de manifiesto la dimensión social y cultural de todo relato personal (Zeldin, 1996; Varela, 2002; Rojas, 2004; Walton, 2005). Estas lecturas me sirvieron para contextualizar mejor el miedo pero carecían de un análisis específico de las diferencias en relación al género. Otras lecturas me ayudaron a completar el cuadro, todas ellas escritas por mujeres (Dowling, 1989; González de Chávez, 1999; Zweig, 2001; Alborch, 2002; Salomon, 2003; Schrierse, 2005).

La idea que comenzaba a tomar más fuerza era construir un relato sobre cómo las mujeres viven y resuelven el miedo a lo largo de su ciclo vital, qué les daba miedo en la infancia, en la adolescencia y juventud, en la madurez y en la vejez y cómo lo resolvían y cómo lo resuelven.

Para ello era necesario que las mujeres me narraran su historia en relación a sus miedos. Mandé un mail a mi lista de correos y aproveché dos viajes fuera de España para entrevistar a algunas. Me mandaron su testimonio por correo electrónico 22 mujeres de distintas edades y nacionalidades y en las dos salidas que tuve en el mes de octubre entrevisté a cinco más: dos asiáticas, una europea, y dos latinoamericanas.

Antes de entrar en el análisis de sus respuestas es necesario establecerlas en un contexto. Decía Freire (Freire, 1989) que el texto sólo adquiere significado en relación al contexto. Comienzo el artículo analizando el patriarcado pues es el contexto en que hombres y mujeres hemos sido socializados y considero necesario, aunque sea someramente, presentar algunas reflexiones en relación al mismo. En un segundo apartado presento las respuestas corporales al miedo y para ello utilizo no sólo lo que dicen las mujeres al respecto sino que también presento algunas investigaciones al respecto. En un tercer apartado presento las voces de las mujeres en relación al miedo en cada una de las etapas de su ciclo vital y el análisis de 
lo que dicen y concluyo el artículo proponiendo una educación basada en el amor como estrategia para formar hombres y mujeres más integrados y más sanos.

\section{El CONTEXTO CULTURAL DEL PATRIARCADO Y SU DECONSTRUCCIÓN}

Mercela Lagarde define el patriarcado en los siguientes términos:

Un orden social genérico de poder, basado en un modo de dominación cuyo paradigma es el hombre. [...] En este mundo, el sujeto no es sólo el hombre, sino el patriarca; los sujetos son los hombres patriarcales (Lagarde, 1996, 52-53).

En el mismo momento en que nacemos y nos nombran como niñas o niños recibimos una serie de referencias normativas para construirnos como hombres o mujeres y para identificarnos con esa construcción, la cual nos acompaña en el desarrollo de nuestra historia personal, que, como dice Lagarde, es siempre historia social. Estas referencias normativas contienen el conjunto de atributos asignados a las personas en función de su sexo biológico y están presentes en cualquier tipo de significación que hagamos como hombres o mujeres.

El patriarcado asignó a las mujeres el espacio de la reproducción y el cuidado de los miembros dependientes de la familia. Las identidades de hombres y mujeres se construyeron por exclusión de unos y de otras. Los límites de la masculinidad se establecieron en las fronteras de lo que significa su opuesto, la feminidad. Hombres y mujeres hemos sido construidos a partir de una serie de mandatos que comienzan a operar incluso antes del nacimiento cuando, gracias a los avances científicos, ha sido posible saber el sexo del bebé. En este contexto las mujeres son entendidas y significadas como emocionales, frágiles, pasivas y vulnerables mientras los hombres, por oposición, lo han sido como fuertes, independientes, racionales y activos.

La modernidad profundizó está oposición y la reforzó con todos los recursos a su alcance. La escuela como institución moderna se encargó de legitimar esta diferencia a través de la socialización secundaria. Rousseau la reforzó y la dotó de autoridad en su tratado sobre la educación de Emilio, prototipo de ciudadano varón, activo, potente y protector de los más débiles. Sofía es la representante del sexo femenino y a ella había que educarla para ocupar el papel que históricamente se le había asignado, a saber: cuidar de los otros, estar para los otros y ser para los otros. Los hombres han sido socializados desde la perspectiva de ser para sí, mientras que las mujeres de ser para el otro.

En este contexto lo importante, lo que tiene valor social es todo aquello relacionado con los hombres y lo masculino. El trabajo de las mujeres y lo femenino no tenían cabida en este sistema y, por tanto, se las dotó de un significado social carente de valor. El mundo emocional, significado como sustancialmente femenino, se excluyó de los procesos educativos y todo lo relacionado con la subjetividad y la emocionalidad se significó como poco práctico. Esto ha producido una realidad 
en la que las esferas de valor masculina y femenina, asignadas a hombres y mujeres, se han construido como opuestos entre sí.

En el último siglo y gracias a la revolución sin armas, que no sin muertas, protagonizada por las mujeres se han producido cambios importantes. El cambio en la identidad de las mujeres está induciendo cambios en la construcción de la identidad de los hombres. Las mujeres llevamos más de un siglo construyendo nuestras nuevas identidades, conscientes de que las verdades absolutas de épocas anteriores se han tornado frágiles.

Las aportaciones científicas producidas por mujeres en las dos últimas décadas están desvelando los errores y las ilusiones del paradigma patriarcal. En los últimos años han surgido nuevos estudios arqueológicos y antropológicos que ponen de manifiesto que a esta sociedad patriarcal, organizada a partir de la exclusión de la mitad de su población y basada en jerarquías de dominio, le precedió otro tipo de organización social basada en la cooperación.

Raine Eisler (Eisler, 2001), revisa la prehistoria y comenta que antes de la aparición del patriarcado hubo 20.000 años de sociedades, no matriarcales como dicen algunos antropólogos, pues eso significaría que el poder estaba en manos de las mujeres y que el sexo masculino estaba subordinado, sino de sociedades de cooperación basadas en la solidaridad. En ellas hombres y mujeres trabajaban juntos, ninguno de los dos estaba por encima del otro, los dos eran igual de importantes para la supervivencia. A partir de los nuevos estudios y descubrimientos arqueológicos y antropológicos Eisler reconstruye el mundo primitivo de colaboración solidaria entre hombres y mujeres. Afirma que posteriormente los hombres que compartían el poder comenzaron a enterrar la verdad sobre la naturaleza igualitaria de la sociedad anterior, de manera que a todo el mundo le pareciera que los hombres habían mandado siempre, como padres, políticos, sacerdotes o Dios. Su conclusión es que la opresión de las mujeres está ligada a la represión de los valores femeninos y para hacerlo efectivo se construye una nueva mitología misógina de héroes y dioses. En palabras de Eisler la civilización de la copa dio paso a la civilización de la espada.

Si Eisler tiene razón entonces no tiene ningún fundamento el temor de los hombres de que el fin de su dominación conduzca inevitablemente a la dominación por parte de las mujeres. Por el contrario, todo parece apuntar a que nos encaminamos hacia una sociedad solidaria en la que no se relacionará ningún género con la inferioridad o superioridad, en la que los valores tanto masculinos como femeninos podrán ser compartidos por unos y por otras.

Mis descubrimientos indican que la nueva integración de las mujeres y la recuperación de los llamados valores femeninos, como la compasión, la no violencia y el cariño en todos los campos de la vida, es uno de los procesos más importantes de nuestra época; un elemento esencial del cambio que necesitamos con urgencia, desde lo que he llamado sistema dominador de organización social hacia un sistema de colaboración solidaria (Eisler, 2001, 55). 
Desde todas las ciencias se están produciendo nuevas hipótesis en relación a qué significa ser un hombre o una mujer en la época actual, se están poniendo de manifiesto cuáles son nuestras similitudes, al mismo tiempo que nuestras diferencias. De lo que se trata en la actualidad, pensamos muchas, es de ir más allá del pensamiento dicotómico y tratar de construir una aproximación integral al tema de la identidad que nos permita descubrir los aspectos masculinos y femeninos en cada uno de nosotros. Hombres y mujeres compartimos una misma humanidad, nos desarrollamos a través de las mismas fases, pero lo hacemos, como diría Gilligan "con una voz diferente" (Gilligan, 1982).

Esa voz diferente también nombra miedos diferentes. Casi todas las entrevistadas coinciden en que no podemos hablar de miedo sino de miedos. Hacen una primera división entre los miedos reales y los mentales. También algunas reconocen que hay miedos que las han acompañado toda su vida y que hay otros que han aparecido en distintos momentos de su ciclo vital.

Antes de seguir adelante he de hacer una aclaración. Las mujeres que me han respondido, si bien pertenecen a distintas generaciones y nacionalidades, comparten un perfil común: todas tienen estudios universitarios, alguna hay que aún cursa sus estudios en la universidad y las otras, la mayoría, son profesionales. Todas son mujeres independientes. Recuerdan infancias felices, sin grandes sufrimientos. Todas las que tienen más de cuarenta años son mujeres comprometidas política y socialmente. Alguna ha conocido la cárcel debido a crisis políticas en sus respectivos países. Otras trabajan para agencias internacionales relacionadas con los derechos humanos en general y con los derechos de las mujeres en particular. Por tanto, quedan fuera de este análisis muchos otros perfiles y, por extensión, muchos otros miedos. A continuación voy a exponer lo que dicen las mujeres en relación a sus miedos ${ }^{2}$.

\section{LA RESPUESTA CORPORAL AL MIEDO Y LA FORMA DE RESOLVERLO}

Las mujeres entrevistadas coinciden en su descripción de las reacciones fisiológicas cuando sienten miedo. También coinciden en que las reacciones corporales ante el miedo dependen de la naturaleza de ese miedo. En este sentido se han expresado metáforas muy gráficas en relación a la diversidad de miedos. Hay miedos que excitan "...pero era un miedo especial, era un miedo como con burbujitas, ése" refiriéndose a las historias de miedo que contaban en su infancia a la luz de un fogata o «era un miedo terrible, terrible, ése, pero era un miedo diferente, un miedo helado, sordo que está como por debajo, después tienes miedo todo el tiempo... era espantoso" para referirse al miedo que sintió durante la dictadura que vivió su país.

2. Por motivos de confidencialidad sólo se hará referencia a la edad y continente de nacimiento. 
Las respuestas fisiológicas al miedo están muy estudiadas y lo que las mujeres narran coincide con lo aportado por otras investigaciones. Veamos alguna:

Una terrible ansiedad, no duermo, sudo mucho, el corazón parece golpear el pecho (Latinoamérica, 71).

Depende, cuando se trata de una situación desconocida o de riesgo la sensación es que se te disparan todos los sentidos y el cuerpo se te acelera. Pero otros tipos de miedos, más psicológicos, más sociales o "construidos" (no sé cómo decirlo), la sensación es diferente. Entonces es como si me apagara (perdiera toda la energía) y necesitara refugio o que alguien me acogiera. En ese tipo de miedos me cuesta mucho más reaccionar (Europa, 39).

Puedo distinguir entre la sensación de miedo a algo inmediato y el miedo generalizado como una actitud o estado de ánimo. En el primer caso siento sensación de opresión en la garganta, aceleración de los latidos del corazón, respiración entrecortada, pulso rápido, cambio de temperatura corporal, dificultad para movierme... En el segundo caso las sensaciones son más amortiguadas pero más duraderas, es decir, no son físicas pero me limitan la acción de cualquier tipo, me impide tomar decisiones, actuar, pensar, podría decir que me embotello, doy vueltas en mi cabeza a lo que me asusta y me cuesta trabajo quitármelo de encima... (Europa, 55).

Palpitación, sudoración, dolor de estómago, pienso muchas cosas al mismo tiempo, depende de la causa del miedo. A veces me paralizo (Asia, 48).

Se manifiesta de distintas maneras: latidos acelerados en el corazón, temblores, angustia, confusión, nervios (Europa, 20).

Éstas son algunas de las respuestas sobre qué sienten las mujeres cuando sienten miedo. Las maneras de resolverlo son diversas, aunque también aparecen algunas similitudes en relación a las estrategias que ponen en marcha para superar el estrés que les produce el miedo. Existe consenso en que esa respuesta está en función de la causa que dispara el mecanismo, si ésta se debe a la necesidad de enfrentar un peligro real inminente o si está relacionada con otro tipo de situación en la que el miedo aparece de manera inducida.

Depende del miedo, en algunas ocasiones con autocontrol, trato de convencerme de que no hay razón para sentir miedo. Cuando el miedo es recurrente suelo hablarlo con amigas. Yo sé que ellas no lo pueden resolver pero, no sé, sólo hablarlo hace que me tranquilice (Latinoamérica, 38).

Hablándolo, respirando, llorando (dejar que salga...), enfrentándome a esa situación, aunque me cueste (Europa, 20).

Hay determinados tipo de miedos que simplemente intento controlarlos racionalizándolos (miedo al ruido de noche, a tener un accidente, etc.). El resto de miedos es diferente, miro de hablarlo con mis amigos y trabajármelos poco a poco. Los amigos siempre te devuelven otra imagen o una imagen más completa. Después 
de hablar y poner un poco de objetividad sobre el miedo, soy más capaz de entender las causas y controlarlas. Aún así hay miedos que perduran y que aparecen de tanto en tanto. Creo que debería ser más constante y trabajar mis emociones, pero, bueno, ya sabes... (Europa, 38).

Hasta que los estudios de género irrumpieron en el escenario científico se pensaba que el miedo producía dos conductas básicas: el ataque o la huida. Esto era debido a que las muestras generalmente eran formadas por hombres y se generalizaban las conclusiones a toda la población. Sin embargo, la investigación con mujeres arroja otros datos, datos que coinciden con la apreciación subjetiva de las mujeres entrevistadas. Sus respuestas están en sintonía con una investigación realizada en la Universidad de California en Los Ángeles, por un grupo de investigadoras (Taylor, Klein, Lewis, Gruenewald, Gurung y Updegraff, 2000) y titulada "Female Responses to Stress: Tend and Befriend, Not Fight or Flight" ("Respuestas femeninas al estrés: Cuidar y hacer amistades, no pelear o escapar"). Este estudio sugiere que las mujeres reaccionamos a las tensiones con una cascada de químicos cerebrales que nos permiten entablar y mantener relaciones con otras mujeres. Hasta que este estudio fue publicado, los científicos creían que cuando las personas experimentan estrés generan una cascada hormonal que las lleva ya sea a pararse y pelear, o a escapar tan pronto como sea posible. Según los científicos esta respuesta es un ancestral mecanismo de supervivencia que nos ha quedado del tiempo cuando tigres de dientes filosos nos perseguían por el planeta.

Sin embargo, esta investigación, cuya muestra estaba formada por mujeres, ha puesto de manifiesto que las mujeres cuentan con un repertorio conductual más amplio que ese de "pelear o escapar". Este repertorio está relacionado con la liberación de oxitocina. De hecho, concluyen las investigadoras, parece ser que cuando la hormona oxitocina es liberada como parte de las respuestas al estrés en las mujeres, ésta amortigua la reacción de "pelear o escapar" y las motiva, por el contrario, a cuidar de niñas y niños, así como a reunirse con otras mujeres.

Indican los estudios que cuando la mujer se involucra en cuidar y en entablar amistades, más oxitocina es liberada, lo cual contrarresta el estrés y produce un efecto calmante. Esta reacción calmante no ocurre en los hombres, afirman, pues la testosterona, que ellos producen en elevadas cantidades cuando se encuentran bajo tensión, parece reducir el efecto de la oxitocina.

Las investigadoras descubrieron que en las investigaciones clásicas sobre el estrés, y el miedo produce mucho estrés, las mujeres no habían sido incluidas y esto suponía un grave error porque esta investigación demostraba que el hecho de que las mujeres respondamos a las tensiones de manera diferente que los hombres tiene implicaciones significativas para nuestra salud.

Cuando las investigadoras analizaron cuán bien funcionaban las mujeres tras la muerte de su cónyuge, descubrieron que aun frente a esta importante fuente de estrés, aquellas que tenían una amiga cercana o confidente presentaban más probabilidades de sobrevivir a esa experiencia sin ningún nuevo impedimento físico o pérdida permanente de la vitalidad. Por el contrario, las que carecían de amigas 
no tenían siempre tanta suerte. Las mujeres que son amigas, concluyen, constituyen una fuente recíproca de fortaleza.

\section{LOS MIEDOS A LO LARGO DEL CICLO VITAL}

Antes de entrar a analizar los miedos expresados por las mujeres a lo largo de su ciclo vital, considero necesario hacer una pequeña introducción a las teorías que utilizo como marco de referencia.

Las teorías psicológicas evolutivas hacen referencia a las distintas etapas por las que los seres humanos vamos pasando a lo largo de nuestro ciclo vital y los tipos de crisis a las que hemos de enfrentarnos para avanzar en el desarrollo de nuestra propia conciencia. Para Jung la primera etapa de la vida se caracteriza por la formación del "yo" mientras que la segunda va dirigida al descubrimiento del "Símismon. Para él el Yo es el intermediario entre la realidad y el Sí-mismo. Pasamos nuestra primera y segunda etapa vital en la construcción del Yo que nos diferencia de los demás. Gracias al desarrollo del Yo vamos construyendo nuestra realidad social. Este proceso dura más o menos hasta la segunda madurez (alrededor de los cuarenta). Hasta este momento, y en esto coinciden casi todos, todas nuestras energías han estado dirigidas hacia fuera, hacia la construcción de una cierta seguridad externa, pero a partir de ahí la mirada se vuelve hacia el interior y uno ha de enfrentarse al descubrimiento del Sí-mismo. Esto supone un viaje a las profundidades, hacia el microcosmos interno, y supone también el enfrentar nuestra sombra como paso previo para encontrar el sentido a nuestra propia vida y llegar al final sabiendo lo que realmente somos.

Según Wilber (Wilber, 1985) cuando uno responde a la pregunta ¿quién soy? sucede algo muy simple. Cuando describe y explica quién es en realidad lo que está haciendo, a sabiendas o no, es trazar una línea o límite mental que atraviesa en su totalidad el campo de la experiencia, y a todo lo que queda dentro de ese límite lo percibe como "yo mismo", o lo llama así, mientras que siente que todo lo que está fuera del límite queda excluido del "yo mismo". Por tanto, al decir "yo" trazamos una demarcación entre lo que somos y lo que no somos y nos limitamos a describir lo que hay en la parte limitada por esa línea. En otras palabras, construir el "yo" implica construir fronteras. La primera frontera que construimos es la corporal: todo lo que está de la piel para dentro soy yo y todo lo que está fuera es lo otro. Por tanto, la piel es nuestra primera frontera, nuestro cuerpo es nuestra primera identidad.

En resumen, en la primera etapa la persona siente que es una con el universo, su verdadero yo no es solamente su organismo, sino la totalidad del universo. En el nivel siguiente el individuo siente que no es uno con el Todo, sino más bien uno con la totalidad de su organismo. Su sentimiento de unidad se ha desplazado y reducido, desde la totalidad del universo a una faceta de éste, a saber, su propio organismo. En el nivel siguiente la identidad vuelve a estrecharse, porque ahora el 
individuo se identifica principalmente con su mente o ego, que no es más que una faceta de la totalidad de su organismo. En este nivel se establecen nuevas fronteras que reducen su identidad a facetas de su mente, alienando y reprimiendo la sombra, es decir, los aspectos no aceptados de su psique. Entonces se identifica con una parte de la psique que es lo que se ha llamado persona o máscara.

Analistas junguianas (Dowling, 1989; Hancock, 2001; Salomón 2003, 2005; Schierse, 2005) han analizado estas etapas teniendo en cuenta la identidad genérica. Parten de la hipótesis de que hombres y mujeres albergamos en nuestro interior aspectos femeninos y masculinos. El patriarcado ha separado lo que en principio se presenta como integrado de tal manera que los hombres proyectan su lado femenino o ánima en las mujeres y las mujeres hacen lo mismo con el ánimus o parte masculina de su propia psique. En este juego de espejos se producen muchas interferencias, mucho ruido y concluyen que el camino a seguir es unir lo que ha sido separado. Construirnos como seres integrados. Veamos a continuación cómo esta separación ha influido en los miedos que las mujeres expresan a lo largo de su ciclo vital. También ha sido determinante en los hombres pero eso es motivo de otro artículo.

\subsection{La infancia}

La primera fase de esta etapa, del nacimiento hasta la aparición del lenguaje, se caracteriza por la fusión del infante con su entorno, principalmente con su madre. Ninguno de los testimonios recibidos o de las entrevistas realizadas hace mención a miedos en los primeros años de vida. Los recuerdos no llegan tan lejos. Sin embargo todas las que hemos tenido hijos e hijas o hemos mantenido una relación estrecha con niños y niñas de esas edades sabemos que alrededor de los 2 años aparecen los terrores nocturnos. Cuando a esas edades mis hijos despertaban gritando de terror hacían referencia a alguna presencia que seguían viendo aun en mis brazos. Los adultos reaccionamos tranquilizando y negando que haya nada ahí $\mathrm{y}$, después de tranquilizarlos, les dejamos una luz encendida. Casi todas las entrevistadas comentan que uno de sus primeros miedos fue el miedo a la oscuridad. También a la posibilidad de que un hombre, siempre un hombre, se esconda en el armario o bajo la cama, a que se las lleve y les haga daño, a defraudar a su padre, a presencias sentidas, etc., veamos algunos testimonios.

Cuando era niña y estaba acostada en la oscuridad tenía miedo de que un hombre estuviera al lado del armario. ¿Qué hacía? Meter la cabeza bajo la almohada (Europa, 50).

Cuando era pequeña, como a todos, me daba miedo la oscuridad. Realmente no tengo recuerdos de pensar en monstruos o en vampiros, más bien en sensaciones. Me daba miedo quedarme sola en casa porque sentía que no estaba sola, y sentir eso me daba pánico. Sentía taquicardia y me metía en mi cama con los cascos de 
música... no me atrevía a moverme de la habitación ni a oír el mundo que me rodeaba (Europa, 22).

Un miedo que me parece que fue más o menos constante en mi infancia fue el miedo a defraudar a la familia, especialmente a mi padre que era del que tenía como más apoyo, más sensibilidad en relación a las cosas que yo hacía. El miedo al abandono creo que es un miedo que comienza en esa época. Creo que es un miedo permanente a lo largo de toda nuestra vida y que una lo aprende a manejar de muchas formas (Latinoamérica, 60).

Recuerdo tener mucho miedo a la oscuridad, de tener miedo a algo así, podríamos decir, como a ladrones, a una figura de un hombre malo que te podía hacer daño (Latinoamérica, 59).

Hay dos tipos de miedo que recuerdo de la infancia y que han aparecido a lo largo de mi vida. Uno es el miedo a la oscuridad y el otro es el miedo a los fantasmas, a las presencias que no puedes ver pero que sientes que están ahí (Asia, 51).

Parece ser, por tanto, que el miedo a la oscuridad, a lo que no se entiende y a que les hagan daño son recurrentes en todas las mujeres entrevistadas independientemente de su edad o contexto cultural.

Cuando reflexionan sobre esto todas recurren a lo que les decían las personas adultas para inducirles el miedo. Las asustaban para que se portaran bien. Las cosas que oían de los mayores coinciden, aun perteneciendo a contextos culturales diferentes. La imagen podría cambiar, a unas les hablaban del hombre del saco, a otras de los espíritus malignos que se las llevarían mientras dormían. El miedo como mecanismo de control está presente en todos los testimonios, puede que la figura que producía miedo no fuera la misma pero todas coinciden en que eran masculinas. La construcción de lo femenino como fragilidad comienza ya en la infancia.

Recuerdo frases como no abras la puerta a ningún extraño, no te pares a hablar en la calle con alguien que no conozcas, etc. Lo que te hace o me hizo profundamente desconfiada. Es esa sensación de que el peligro siempre te acecha y que los hombres (sobre todo los hombres) desconocidos si se acercan a ti es que no son de fiar. También otro tipo de frases: si no te portas bien vendrá el hombre del saco y se te llevará. Así que imaginaba que en cualquier momento aparecería un hombre con un saco muy grande cargado de niñas y que me llevaría con él a un sitio oscuro y frío (Europa, 38).

Cuando querían disciplinarme, por ejemplo cuando me iba lejos de la casa me decían que los fantasmas iban a llevarme. También recuerdo que en todas las casas en las que viví venían mis tías y mi abuela y nos decían que sentían que había un espíritu allí y que no debíamos perturbarlo. Y entonces mi madre se murió cuando yo tenía 12 años. Fue muy traumático, murió en un accidente a los 32 años y todas mis tías nos decían que mi madre estaba con nosotros en la casa y que su espíritu cuidaría de nosotros. Yo sabía y sentía que ella estaba conmigo, me daba mucho miedo pero me daba mucho más el pensar que podía verla. Mis tías me decían que 
ellas veían su espíritu y yo tenía mucho miedo a que me sorprendiera. Yo no la veía pero la sentía y le pedía que cualquier cosa que quisiera decirme lo hiciera en los sueños (Asia, 51).

Emily Hancock (Hancock, 2001) nos comenta que si ha habido un desarrollo "normal" las niñas entre ocho y diez años son inocentes, poderosas y alegres, pero que a partir de esa edad se vuelven autocontroladas y responsables. En su libro, "La niña interior" nos describe detalladamente el proceso de cómo hacia la pubertad el condicionamiento de la cultura patriarcal para que se convierta en lo que se espera de ella ya ha concluido.

\begin{abstract}
Al final de la infancia la niña ya ha interiorizado la identidad que le asigna la estructura patriarcal. Hasta que tiene ocho o nueve años crece con relativa libertad, es la época en la vida de una mujer en la que con más frecuencia está aliada con su padre y, paradójicamente sin embargo, es el periodo en que está menos definida por el patriarcado. En este momento de la vida de las mujeres el cielo es su único límite, sus anhelos y sus objetivos son infinitos; absolutamente todo es posible. Las contradicciones no la frenan: futura arqueóloga y abogada, practicará durante el invierno la abogacía e irá a hacer excavaciones arqueológicas al llegar el verano. Tanto si sueña con ser oceanógrafa como astronatuta, gobernadora, neurocirujana, directora de orquesta, presidenta de un banco o juez, es apoyada idealmente por los demás en la visión que tiene de sí misma en el futuro. Rara vez sus metas son sometidas a críticas; sus decisiones no comportan todavía pérdidas; sólo más adelante una elección supondrá dejar otra de lado. Su experiencia de niña abarca hombre y mujer, trabajo y juego, independencia y dependencia, sin que ningún término esté subordinado al otro. Libre de las convenciones femeninas, puede pensar, planificar y hacer (Hancock, 2001, 99).
\end{abstract}

\title{
4.2. La adolescencia y juventud
}

Éste es el momento en que comienza a manifestarse la cultura de los recortes cuyo objetivo es cercenar los sueños infantiles de grandeza en aras al principio de realidad. A medida que la cultura traza la línea divisoria entre pequeño y grande, juego y trabajo, mujer y varón, sus agentes se ven obligados a intervenir. Hay que domesticar a la joven salvaje y hacer que asuma los patrones tradicionales de la mujer como nutridora y cuidadora. Sus sueños ahora resultan amenazantes. Aquellos que hasta ahora la habían animado para que persiguiera sus sueños son ahora los encargados de hacer que los olvide. Poco a poco todos sus sueños anteriores van sometiéndose a valoraciones y juicios y sus mayores desinflan sus ideas grandiosas considerándolas irrealistas. De esta manera se la va moldeando. Se rompe el vínculo entre lo que ella hace y lo que es y poco a poco va abandonando el Hacer en aras del Ser una buena chica. Impresionada por la importancia de las opiniones ajenas, se moldea a sí misma conforme a lo que los demás quieren que sea. El principio de realidad se impone y los miedos en esta época comienzan a estar relacionados con lo que los demás pueden pensar de ellas, a que las valoren 
negativamente, a que las rechacen o a que las juzguen como incapaces. Su identidad como niña poderosa se ha hecho añicos.

Así pues, los miedos de las mujeres adolescentes están relacionados no ya con sus propias fantasías sino con la fantasía de los otros. Además algunos de los miedos de la infancia permanecen aunque se desplazan en su simbología. Si en la infancia aparecía el miedo difuso a un hombre que pudiera hacerles daño, en la adolescencia ya tiene imágenes y el miedo a que abusen de ellas o a que les hagan daño es bastante común.

Cuando comencé a salir de la familia tenía miedo a los nuevos círculos, miedo a las críticas o burlas (sobre todo de las que era más amigas o de los chicos da igual si amigos o no). Miedo a hacer el ridículo, claro, miedo a los comentarios irónicos sobre mí. Miedo a ser amiga de todos pero de ninguno, de estar sola, básicamente. Igual no era miedo, pero sí recuerdo que en este aspecto era muy infeliz. Lo resolví con el tiempo (Europa, 25).

En la adolescencia los temores van vinculados al temor a no gustar a los chicos, a no lograr integrarme en las pandillas, a todo lo relacionado con la sexualidad... Cuando comienzan las relaciones con los chicos: a los avances sexuales de los chicos, primero, luego, superados los primeros temores de contacto en aquellos tiempos oscurantistas y ya en plena juventud, aparte de los vinculados a las relaciones con los varones y al temor a que te pudieran utilizar o "abusar" (Europa, 53).

Me casé siendo virgen y eso me creó, no sé si llamarlo miedo o ansiedad, yo creo que era ansiedad. Esta ansiedad estaba relacionada con el sexo, era como estar fuera de mí, no sé cómo describirlo, tenía mucha ansiedad al principio sobre todo esto. Si no tenía interés me creaba la ansiedad de ¿seré una mujer? Sabes, a lo mejor no soy una mujer completa y cosas así (Asia, 49).

En mi juventud, quizá con 17 ó 18 años, miedo a ser violada, miedo a volver a casa de noche, en la oscuridad. Ya no recuerdo si esos miedos los tenía yo misma en realidad, o se trataba de la carga negativa que mi madre me transmitía. Nuestra madre nos bombardeaba a mi hermana y a mí los oídos con avisos terroríficos y sermones morales. No nos ayudó demasiado a convertirnos en mujeres adultas felices. Lamentablemente, mi madre estaba poseída por sus miedos. Era difícil encontrar un camino propio a través de aquello. Pero mis ganas de vivir eran superiores. Sólo que el precio era muy alto (Europa, 50).

De adolescente mis pesadillas siempre estaban relacionadas con tragedias que pudieran pasarles a mis padres y me daba cuenta hasta qué punto podía llegar mi malvada imaginación. Que también me jugaba malas pasadas cuando caminaba sola por la calle, parece como si de repente todo el mundo te fuera a hacer algo a partir de que se ponga el sol. En relación a mis amigos pensaba si no sería lo suficientemente guapa, graciosa, buena, etc. Me daba miedo lo que los demás pensaran de mí y no destacar en ninguna actividad (Europa, 22). 


\subsection{La adultez}

En esta etapa los miedos de las mujeres entrevistadas están relacionados fundamentalmente con tres ámbitos: el amor en la pareja, la maternidad y el desarrollo profesional que a su vez hacen referencia a la división entre el espacio privado y el espacio público. Los roles tradicionales en relación a lo que significa ser una buena madre y la necesidad de desarrollar sus expectativas profesionales entran en conflicto. Incorporarse al mercado de trabajo es romper con el mandato patriarcal de que el lugar de las mujeres es el hogar y de que su principal función social es el cuidado de los otros. Para que esto se cumpliera adecuadamente el sistema patriarcal ha hecho creer a las mujeres que ellas no eran lo suficientemente buenas, lo suficientemente listas o lo suficientemente racionales para ingresar en un espacio que ha sido históricamente el espacio masculino por antonomasia. Este espacio ha sido construido, pensado y estructurado bajo la lógica masculina. Al haber sido las mujeres definidas por el otro masculino como emocionales, ilógicas y subjetivas ha producido que las mujeres más mayores que se incorporaron al espacio público en los años sesenta-setenta reconozcan que esta etapa de sus vidas se caracterizó por nuevos miedos y que éstos estaban relacionados principalmente con su propia estima y sus propias capacidades.

Estaba trabajando en una ONG y entonces comencé a preguntarme y ahora qué, yo era una activista, quería cambiar cosas, quería investigar, quería hacer activismo y todo esto me llevaba a preguntarme cómo voy a combinar todo esto en uno, cómo voy a hacerlo todo. Esto me producía ansiedad porque quería hacerlo todo y quería hacerlo perfecto. Sabes, hacerlo todo bien (Asia, 49).

Profesionalmente, en una situación difícil en 1993/94, era responsable de una organización con una grave crisis financiera, en caída libre (que caía en picado). No tenía ni idea de qué hacer, y por momentos me atrapó el pánico, el miedo a mi propia existencia, al patinazo social, a la miseria en mi vejez. Miedo a ya no ser capaz de ganar mi propio sustento. ¿Qué hice para superar este pánico? Después de llorarle hasta no poder más, una amiga me preguntó: Bien, ya has llorado, ahora ¿cuál es tu estrategia? (Europa, 50).

También comentan que en esta época de sus vidas experimentaron muchos miedos relacionados con sus puestos de trabajo y que ellos funcionaron como disparador de su conciencia feminista. Coinciden que este espacio no las reconocía como competentes, que tuvieron que desgastarse mucho hasta conseguir que se las respetara. Algunas manifiestan que esta lucha las fortaleció como mujeres, pero otras reconocen que tuvieron que cambiar de trabajo porque se les hacía insoportable la presión a la que las sometían sus compañeros varones. Veamos un testimonio en este sentido:

Cuando empecé a trabajar en una empresa que se dedicaba al comercio exterior, me sentía feliz. Era mi primer trabajo y tenía mucha responsabilidad. Tenía 26 años 
en aquella época. Pensaba que estaba preparada, hablaba tres idiomas, y que era competente profesionalmente. Al principio todo bien. Me sentía importante, algunos compañeros hacían algún comentario sobre si estaba guapa y esas cosas. Estos comentarios me halagaban pero pronto empezaron las miradas que te hacían sentir desnuda y los comentarios ... Las miradas, no sé cómo describir esas miradas, sólo sé que sentía que me rompían por dentro, me paralizaban, y cosas así. Comencé a dormir mal, a tener miedo de ir a trabajar. Aquella época fue terrible, terrible. Nada más levantarme y pensar que tenía que ir a trabajar me sentía morir. Comencé a cambiar mi manera de vestir para no dar lugar a ningún comentario desagradable. Llegué a pensar que todo estaba en mi cabeza y que era yo la que los incitaba. Si me enfadaba me decían que era una broma cariñosa que no tenía que ponerme de esa manera, que no tenía sentido del humor... pero para mí aquello no eran bromas, esos comentarios me hacían sentir insegura y sucia. Cuando llegaba a casa después del trabajo me sentía mal, de mal humor, muy cansada y sin ganas de nada. Sólo me apetecía meterme en la cama y llorar. Tuve que cambiar de trabajo (Europa, 50).

Este testimonio pone en evidencia el tema del acoso de género, que consiste en tratar a una mujer de un modo distinto por el mero hecho de ser una mujer. Hace 25 años estas conductas se consideraban "normales". Nadie hablaba sobre el acoso. Es a principio de los noventa cuando comienza a nombrarse. Marie-France Hirigoyen lo define en los siguientes términos:

Por acoso en el lugar de trabajo hay que entender cualquier manifestación de una conducta abusiva y, especialmente, los comportamientos, palabras, actos, gestos y escritos que puedan atentar contra la personalidad, la dignidad o la integridad física o psíquica de un individuo. [...] El acoso nace de forma anodina. Al principio, las personas acosadas no quieren sentirse ofendidas y no se toman en serio las indirectas y las vejaciones (Hirigoyen, 1999, 48).

Tradicionalmente el espacio público era donde el hombre construía su identidad como hombre, por lo que la incorporación de las mujeres en este espacio fue considerada por muchos como una intromisión y como fuente de conflicto. La competencia se establecía entre hombres, ¿cómo iba a ser que ahora ellos, inteligentes, racionales y activos, tuvieran que competir con mujeres a las que se consideraba carentes de los atributos que los definían? Los significados culturales en relación a su masculinidad les hacían difícil tomarse la competencia de las mujeres en serio. Al seguir pensando en el fondo de sí mismos que las mujeres eran frágiles llevó a muchos a desarrollar relaciones de trabajo basadas en el paternalismo. Las mujeres se desgastan para ser reconocidas como iguales profesionalmente y sienten que es tan imposible como derribar un muro con un soplo. Las mujeres que han tenido puestos de responsabilidad y, por tanto, hombres a su cargo, reconocen las dificultades y la energía gastada en hacerse respetar por sus subordinados hombres. Nada era explícito, todo ocurría en el plano simbólico. Además cuando llegaban a casa debían responder a las múltiples demandas de la vida familiar. 
Lagarde nos dice que las mujeres contemporáneas sintetizan cada día una doble vida y no sólo una doble jornada: dobles espacios, dobles tiempos, actividades simultáneas, normas y códigos de comportamientos distintos y contradictorios. Cada mujer debe desarrollar habilidades para pasar de unas dimensiones vitales a otras sin equivocarse. Aprender a estar subordinada y con poderes reducidos en un ámbito y, al mismo día, transitar a otro espacio, ocupar posiciones de mando, cumplir con responsabilidades, tomar decisiones y además tener éxito. La doble vida implica, por tanto, la capacidad de reaccionar ante identidades asignadas diversas y contradictorias, cargadas de expectativas que se entrecruzan y chocan. Crisis y conflictos de identidad desgarradores expresan esta escisión que las mujeres interpretan como errores, incapacidad, fallas. Se sienten fallidas cuando incumplen por falta de tiempo, por saturación, por tensión vital y son descalificadas como inadecuadas, como locas (Lagarde, 2000, 49).

Era mucho, trabajaba todo el día en la calle y cuando llegaba a casa tenía que seguir trabajando porque mi marido no hacía nada. Siempre que manifestaba mi enfado por su pasividad terminaba sintiéndome culpable... él era muy hábil dándole la vuelta a todo. Nos separamos y entonces el pánico ante la sensación de agujero negro, de incógnita, de lo desconocido, la inseguridad... la soledad... el sentimiento de fracaso... (Latinoamérica, 55).

Me casé porque estaba embarazada. Mi miedo principal en esta época era a sentirme atrapada, a no ser yo misma. Me separé después de nueve años. Fue duro volver a empezar. No me pude divorciar porque era ilegal el divorcio pero luego tuve otras relaciones que tampoco funcionaron. Tal vez por ese miedo que te digo a sentirme atrapada, cogida. He tenido cinco hijos con tres hombres distintos. Como mi primer marido murió ahora soy viuda (Asia, 49).

El miedo a la soledad está relacionado con la pérdida del amor y esto produce terror en las mujeres cuya identidad ha sido construida percisamente a partir de este sentimiento. Además el sistema patriarcal utiliza una doble vara de medir y mientras a un hombre solo se le considera un soltero de oro, a una mujer sola se la considera una fracasada. No es extraño que las mujeres que se han separado de sus parejas sientan que han fracasado y esto les produzca un miedo atroz, no sólo por lo que socialmente puede pensarse sobre ellas sino también y sobre todo, por la pérdida del vínculo amoroso. Las mujeres han sido socializadas para dar amor a los otros, no para amarse a sí mismas. Amarse a sí mismas ha sido un aprendizaje tardío que muchas comenzaron a partir de sus crisis matrimoniales.

Me separé después de veinticinco años. Al principio creí morir, no sabía si iba a ser capaz a mi edad de vivir sola, nunca lo había hecho. Todo me daba miedo, siempre pensaba que no iba a ser capaz. Fíjate que tontería pero ir sola al cine o a un restaurante me producía pavor. Me daba vergüenza, pero yo me obligaba y me decía a mí misma que no pasaba nada, que todo estaba en mi cabeza. Necesité más de un año para sentirme a gusto en mi piel y en mi casa. Me sometí a un 
proceso terapéutico y participé en muchos talleres de autoestima. Hoy soy otra (Europa, 48).

Desde hace varias décadas, mujeres de todo el mundo han planteado la necesidad de reparar las heridas y eliminar los sufrimientos provocados por la violencia simbólica o explícita ejercida sobre ellas. En los testimonios recibidos se desprende que esta violencia se ha ejercido en el plano simbólico, pero ya dije que estas mujeres representan un perfil social y cultural muy concreto. Ninguna ha sido maltratada físicamente aunque sí reconocen que su lucha por ser ellas mismas les ha producido daños psicológicos profundos relacionados con su propia estima. Reconocen que su participación en talleres organizados desde el feminismo les ayudó en el desarrollo de una conciencia de sí y amplió su conciencia crítica en relación a la construcción de la identidad de género. Compartir con otras mujeres su propia historia las ayudó a tomar conciencia de que lo personal es social y político y esto las impulsó a comprometerse políticamente con la causa de las mujeres y a descubrir muchas de las mentiras en las que se sustenta el sistema patriarcal en relación a lo que ellas son.

En los talleres sobre autoestima las mujeres nos hemos atrevido a mirar nuestros miedos, a nombrar desde nosotras mismas nuestros conflictos, a valorar nuestras cualidades y nuestros logros. Esto nos ha permitido conocer lo oculto y lo silenciado. Hemos roto la barrera del silencio impuesto y en una atmósfera de confianza hemos hablado de nuestros dramas de vida y de nuestros hallazgos y hemos delineado anhelos. Hemos hecho catarsis y hemos comprendido, analítica y afectivamente, que la fuerza de las cosas es domesticable, que la naturaleza no es destino, que eso no sólo me pasa a mí o que eso a mí no me pasa, y que es posible crear caminos individuales y colectivos para avanzar. Ahí, en la confrontación con la vida, hemos aprendido feminismo y hemos bebido de dos de sus fuentes: la experiencia práctica feminista inventada por las mujeres de a pie, y el feminismo ilustrado (Lagarde, 2000, 69).

Compartir la experiencia y la conciencia ha sido fundamental para las mujeres. El pequeño grupo nos ha servido para reflexionar sobre nuestras vidas en un ambiente cálido y de confianza y sin sentirnos juzgadas por el otro masculino. Estos encuentros nos han permitido mirarnos y encontrarnos sin mediaciones, oír nuestra propia voz, pensar por nosotras mismas y para nosotras mismas. Hemos aprendido a nombrarnos genéricamente y a querernos y hemos descubierto la soriridad. Si queremos diferenciarnos, tenemos que reclamar la legitimidad de nuestra propia experiencia. Tenemos que re-conocer cómo y por qué construimos nuestras experiencias como mujeres. Es aquí donde el feminismo nos ayuda psicológicamente: en descubrir nuestro propio discurso y diferenciar nuestras experiencias de las instituciones patriarcales. El feminismo ha sido una buena herramienta para deconstruir y reconstruir nuestros significados existenciales.

La maternidad es otra de las fuentes de las que brota el miedo en las mujeres y éste suele estar relacionado con la incapacidad para cumplir las expectativas 
culturales de lo que significa ser una buena madre. Las mujeres jóvenes viven esto de manera contradictoria. Han vivido la doble vida de sus madres, son conscientes de su deseo de experimentar la maternidad, al mismo tiempo que saben que eso frenará su desarrollo profesional. Retrasan su maternidad en aras a su desarrollo profesional y esto también les produce miedo pues saben que su reloj biológico tiene fecha de caducidad. A esto hay que añadir sus dificultades para encontrar al hombre que sueñan, pues los hombres de su generación y perfil, siendo más sensibles a las injusticias de género, siguen reproduciendo muchos de los roles con los que en teoría están en desacuerdo.

Cuando tenía 29 años tenía un novio con el que convivía desde hacía siete años. Entonces cambié de trabajo y comencé a viajar mucho. Al principio él me apoyaba pero luego empecé a notar que mis salidas le molestaban. No decía nada pero yo sentía que se ponía de mal humor y comenzaron los comentarios de si viajaba mucho, de si se sentía solo, etc. Estos comentarios me hacían sentir mal, me sentía culpable porque se quedaba solo, me decía a mí misma que él tenía razón. Trataba de hablarlo y de explicarle que éste era mi trabajo, él decía que lo entendía pero yo sabía que no, que en el fondo le molestaba. Duramos un año más. Luego he tenido tres novios más y con todos me ha pasado lo mismo y eso que cuando los conocí yo ya viajaba mucho. Ahora tengo 38, me gusta el trabajo que hago y quiero ser madre. Ya no me queda mucho tiempo, me sorprendo pensando que si quiero tener una relación estable y tener hijos, tengo que cambiar de trabajo (Europa, 38).

Las mujeres que fueron jóvenes en los 70 no tuvieron estos miedos pues casi todas ellas fueron madres siendo más jóvenes. Todas las mujeres que han sido madres coinciden en que la maternidad despertó en ellas nuevos temores. Por un lado a no ser buenas madres y, por otro, a que algo malo les pase a sus hijos.

Uno de los miedos que para mí fue muy fuerte durante el embarazo fue por un lado, claro, el miedo a ver cómo podía cumplir con el rol de madre que yo ya estaba cuestionando, a pesar de que no era feminista en aquella época, pero sentía que yo quería seguir estudiando, quería ser profesional, quería hacer una vida como más autónoma. Entonces el embarazo me produjo muchos miedos. Miedo de no ser, de no cumplir con las normas de una buena madre y claro, miedo por ser responsable de la vida de una cosita tan indefensa como es un bebé (Latinoamérica, 60).

...a que les hagan daño a alguno de mis hijos o les pase algo malo y sufran, a no estar ahí cuando me necesitan... (Europa, 43).

Tengo miedo a que mi hija se ponga enferma y sufra. Ese miedo está ahí siempre, latente, me acuerdo a veces pintándome escenarios horribles y entonces los rechazo, expulsando esos pensamientos, aunque normalmente no me acuerdo sin algo externo que lo dispare: la noticia de otro niño enfermo, las imágenes de televisión... (Europa, 47). 
Como madre por supuesto estaba llena de miedos y ansiedades, la primera estaba relacionada con el hecho de ser madre. Tener un bebé, no tener experiencia en cuidar de alguien tan pequeño que depende totalmente de ti. Luego los miedos sobre su salud, a que se pusiera enferma. Después cuando la puse en una guardería, pensaba si cuidarían bien de ella y esas cosas. Luego relacionado con mi hija cuando ella tuvo su primera regla fue un miedo y una ansiedad sobre si ella sería lo suficientemente buena para arreglárselas sola con los chicos, si, no tengo ningún prejuicio en relación al sexo y eso pero creo que, y bueno así se lo dije. Le dije "mira ahora que estás creciendo vas a tener estos intereses pero tienes que estar segura de que estás preparada para esto. Que tienes que estar física y psicológicamente preparada para saber en lo que te metes y tienes que hacer que te respeten, no que abusen de ti". Bueno eso eran mis miedos y creo que se los comuniqué y si... pero ella ha tenido unas experiencias muy negativas con los chicos, no se ha sentido respetada. Bueno, esto era otro nivel de miedo (Asia, 49).

También es en la adultez cuando aparece el miedo a la enfermedad o las primeras experiencias con ella. También comienza a emerger la conciencia de finitud. El cáncer es la referencia más común cuando hablan o escriben sobre el miedo a la enfermedad. Este miedo se presenta en dos ámbitos: en relación a los otros, a los que dependen de ellas y en relación a la pérdida de su feminidad si hay que someterlas a alguna amputación.

Cuando estaba comenzando mis 30 tuve terribles hemorragias, sangraba y sangraba y tenía un dolor terrible. Fui al médico y me dijo que tenía que operarme y hacerme una histerectomía y sabes cuando estás al principio de los 30 sientes que eres muy joven para que te quiten el útero y entonces dije no. No es que tuviera miedo de una operación pero estaba muy ansiosa, había probado distintos tratamientos pero llevaba tres años sufriendo y al final tuve que ir a una operación y me preguntaba: oh ¿volveré a ser una mujer otra vez despues de esto?, ¿cómo afectará a mi vida sexual, qué me va a pasar? ¿Si me muero quién cuidará de mi hija? Pero luego todo fue bien, nada pasó. Otro miedo era con la menopausia inducida, porque si la menopausia sucede cuando tus ovarios dejan de producir hormonas, con la histerectomía lo que sucede si te quitan los ovarios es que te provocan una menopausia. Creo que éste era un miedo positivo porque hablé con mi médico y le dije que no podía tocarme los ovarios, que podía quitarme el útero pero que tenía que dejarme los ovarios, porque no quería ir hacia una menopausia. Me dijo que eso era un riesgo y yo le dije que sí que asumía el riesgo. Así que éste fue un buen miedo que me ayudó a tomar una buena decisión en relación a mi cuerpo (Asia, 49).

Tengo miedo a coger un avión, a tener un cáncer y no poder cuidar de mi hija. Tengo miedo a las drogas y a que mi hija no sea feliz (Europa, 33).

Soy madre soltera, tengo una hija de ocho años y me aterra pensar que pueda pasarme algo y no poder cuidar de ella, ¿quién lo haría? (Europa, 47).

El final de esta etapa coincide con la menopausia que en el contexto cultural patriarcal se asocia a pérdida: pérdida de capacidad reproductiva, pérdida de 
capacidad de seducción, pérdida de salud, pérdida de los hijos, etc. No es extraño que en general las mujeres vivan esta etapa con miedo y en completa soledad.

En los últimos años y gracias a los relatos de muchas mujeres y a nuestro trabajo en la fase anterior con nosotras mismas comprendemos que no todo son pérdidas, que también hay ganancias. Muchos de los miedos que poblaron nuestra juventud se suavizan, hemos aprendido a enfrentarlos, a deconstruirlos y nos damos cuenta de que nos estamos convirtiendo en mujeres más libres y más sabias (Hall y Jacobs, 1994). Comenzamos a ver la vida desde otra perspectiva más dinámica, nuestra intuición se expande y ya hemos aprendido el valor de guiarnos por ella aunque la cultura patriarcal le dé escaso valor. A los cincuenta comprendemos nuestro poder y lo usamos.

\subsection{La vejez}

La vejez es el momento de la recapitulación, de hacer balance sobre la propia vida y de la toma de conciencia de la finitud. Aparece el miedo a la muerte con toda su virulencia, la certeza de que el tiempo que queda es limitado. Los miedos en esta fase se relacionan con la pérdida de autonomía, con la dependencia, con ser o no capaces de vivir una vejez con dignidad y con la soledad. Pienso que estos miedos también están presentes en los hombres. La diferencia estriba en la manera de vivirlos. En la actualidad la mayoría de los hombres de 60 y más años viven esta etapa con una mujer a su lado. Sin embargo, no ocurre esto con las mujeres de estas edades las cuales bien porque se han quedado viudas, bien porque se han separado saben que tendrán que enfrentar esta etapa solas. Están los hijos, pero las mujeres del perfil analizado han educado a sus hijas e hijos en otros valores distintos a los de la familia tradicional patriarcal. Entienden que en la complejidad del mundo actual no pueden esperar de sus hijos que cuiden de ellas. Además el valor de la libertad ha guiado sus vidas y no están dispuestas a renunciar a ella. Imaginan respuestas creativas para pasar por esta etapa con la mayor dignidad y autonomía posible. Veamos algunos testimonios:

Lo que cambió es que ya no tienes la sensación de infinitud ¿sabes?, de que ya está el límite ahí, ¿no? Y entonces ese reconocimiento es un proceso complicado, ¿no? Porque es el reconciliarte con el hecho de que tu vida comienza a tener descuento permanente, que ya no es ese horizonte infinito que tenías antes, claro, y eso, eso produce... me trae otros miedos. Me trae un miedo, por ejemplo, a, a este..., quería decir el miedo de muchas de nosotras las mujeres que tenemos una vida autónoma, que no tenemos una relación tradicional ¿no? Y entonces por eso, varias de nosotras hemos comenzado a pensar, a soñar la posibilidad de tener, para matar estos miedos de la soledad en la vejez, tener una especie de asilo feminista ino? Estar todas las que estamos más o menos en la misma situación, ver cómo podemos hacer para tener una vida autónoma, independiente y al mismo tiempo estar suficientemente cercanas, como cuidándonos ¿no? En esa especie de solidaridad básica que podemos tener las mujeres ¿no? (Latinoamérica, 60). 
Los miedos con el envejecimiento giran en torno a la incapacidad física... el miedo a la dependencia, la falta de libertad, la imposibilidad de valerte por ti misma... En relación a las relaciones con los hombres, la certeza casi absoluta de que no podría encontrar una pareja si terminase ésta, porque ni ellos querrían a una como yo (vieja y feminista), ni yo encontraría/desearía empezar de nuevo. La verdad que el miedo a envejecer lo veo vinculado a esos dos aspectos: la pérdida de la fuerza física y la pérdida de la capacidad de seducción... (Europa, 53).

Ahora tengo miedo a la enfermedad, la mutilación, el quedarse dependiente de los demás, perder amigos y parientes, la violencia, la muerte... El miedo a la muerte (lo desconocido) lo resuelvo pensando que el secreto es esta frase que la repito siempre que me asalta ese tipo de miedo: "Hay que vivir sin pensar en la muerte; hay que morirse sin pensar en la vida" (Latinoamérica, 71).

Los testimonios recibidos y los relatos escuchados presentan demasiadas coincidencias, al mismo tiempo que son únicos. Son experiencias personales y, simultáneamente, transculturales y colectivas. El hecho de ser mujeres es lo que nos hermana, el hecho de compartir un mismo perfil sociológico, lo que nos iguala, independientemente del contexto local en el que cada una se ubique. El patriarcado es una constante cultural universal, él es la malla en la que se han tejido nuestros miedos y nuestros sueños.

El feminismo nos ha permitido volvernos conscientes de lo que históricamente ha sido invisibilizado, nos ha mostrado la matriz de la cultura patriarcal, nos ha ofrecido algunas herramientas conceptuales para entender qué significa ser una mujer en este contexto y nos ha mostrado el camino para transformarnos individual y colectivamente. Hemos podido comprender que los atributos femeninos fueron desvalorizados y, con ellos, nosotras como mujeres. Al igual que Metis, fuimos tragadas por el discurso del patriarcado.

Las mujeres contemporáneas estamos reflexionando sobre qué es realmente lo femenino. Estamos buscando, hablando entre nosotras, intentando poner voz a nuestras experiencias, a nuestros sueños y a nuestros miedos. Muchas sentimos y experimentamos lo femenino, pero aún carecemos de palabras para expresarlo porque nuestro vocabulario y nuestros conceptos han sido elaborados por el otro masculino. La construcción de lo femenino desde las mujeres se ha convertido en un gran reto.

\section{A MODO DE CONCLUSIÓN: HACIA UNA PEDAGOGÍA DEL AMOR}

La educación tiene un papel importante que cumplir en la construcción de seres humanos más integrados y sanos. En las sociedades de la información el debate sobre qué tipo de educación necesitamos para el siglo XXI ha pasado a primer plano. ¿Ha de ser una educación que se base en la transmisión de una selección de contenidos más o menos arbitrarios o, por el contrario, ha de ser una educación que nos sitúe en los grandes mapas y nos ayude a resolver los conflictos 
en los que como humanidad estamos inmersos? En la actualidad existe una disociación profunda entre, por un lado, nuestros saberes desarticulados, fragmentados, compartimentados en disciplinas y, por el otro, las realidades y problemas cada vez más interrelacionados, multidimensionales, transnacionales, planetarios y globales y esto nos hace incapaces de captar lo que está tejido conjuntamente (Morin, 2001).

Enseñar la condición humana, nos dice este autor, pasa por integrar nuestra naturaleza física, biológica, cultural, social e histórica. Aprender lo que significa ser humano lleva a tomar conciencia de esta identidad compleja y, al mismo tiempo, común al resto de los seres humanos. Para que hombres y mujeres podamos construirnos como seres humanos iguales, primero hemos de aclarar cuáles son las diferencias existentes entre las esferas de valor masculina y femenina, luego aprender a valorar esas diferencias por igual para integrarlas y poder trascenderlas. Ambas son necesarias y ambas son igualmente valiosas. El reto consiste en reconocer las diferencias sin utilizarlas, una vez más, para coartar los derechos de las mujeres. Porque suele ocurrir que apenas se proclama la existencia de algún tipo de diferencias entre las personas, los más privilegiados suelen usarla para perpetuar sus privilegios.

La educación debe facilitar la construcción de estas nuevas identidades que posibilitarán una nueva manera de relacionarnos, de reconocernos y de respetarnos. Para ello hemos de enfrentar enormes resistencias culturales, pues la visión del mundo masculina, aunque está debilitándose, sigue siendo hegemónica.

Para Claudio Naranjo el patriarcado es la raíz común de todos nuestros problemas actuales, que aunque aparentemente se haya debilitado sigue gozando de una enorme capacidad de penetración en todos los ámbitos de nuestras vidas. Está en la base de la mentalidad industrial, del capitalismo, de la explotación de los recursos naturales, de nuestra incapacidad de vivir en paz, etc. La primacía de la competitividad sobre la cooperación, de la razón sobre la emoción o de lo masculino sobre lo femenino son prueba de ello. Ir hacia visiones más integrales supone poner en cuestión todo aquello que venimos haciendo desde hace milenios.

Una señal de cuán patriarcal es la educación tradicional (a pesar de la natural asociación de la vocación docente con el espíritu maternal) es que en las innumerables propuestas educacionales que se elaboran esté sistemáticamente ausente la palabra amor. Aun cuando la discusión tome en consideración la importancia de una educación interpersonal. De una educación que fomente el sentirse parte de una comunidad, del desarrollo de un sentimiento cívico, parecería que palabras como "Compasión" o "amor" fuesen implícitamente tabú. Veo en esto el imperio de la ciencia y del racionalismo propio de la cultura patriarcal: los asuntos de amor se consideran demasiado románticos, tal vez pertinentes al arte pero no a una "Conversación seria". Ello indica, me parece, que aún después de décadas de feminismo durante las que se ha logrado bastante progreso en materia de derechos de la mujer tanto en lo laboral como en el terreno político, no es tanto lo que se ha logrado cuando se trata de un equilibrio entre los valores masculinos y femeninos. 
Es bastante posible solucionar asuntos que tienen que ver con la injusticia de género dándole poder a la mujer, sin tocar el asunto fundamental, que es justamente la preferencia del poder sobre el amor (Naranjo, 2004, 126).

En efecto, en la Ley Orgánica 2/2006 de Educación la palabra amor no aparece ni una sola vez. Se habla de diversidad, de equidad, de calidad, de esfuerzo, de solidaridad, de responsabilidad, de tolerancia, de paz, de igualdad, de justicia, de no violencia, de respeto, de inclusión, de ciudadanía, de democracia, de convergencia, de flexibilidad, etc. Pero no de amor, ni de compasión, entendiendo por compasión la capacidad de sentir-con.

Esta ley presenta algunos avances en relación al reconocimiento de la igualdad entre hombres y mujeres y también al reconocimiento de la diversidad. Sin embargo, al no reflexionarse sobre las razones que nos han traído al momento actual, al no desenmascarar los errores y las ilusiones con los que hemos construido nuestras cosmovisiones, al no entrar en las estructuras profundas que determinan nuestra comprensión de la realidad y al seguir compartimentado el saber en disciplinas desconectadas unas de otras, lo que producirá será un cambio superficial porque las jerarquías de dominio que rigen las estructuras profundas seguirán activas. Aunque la nueva ley explicita el interés por la ecología, el desarrollo sostenible, la paz, la no discriminación, etc., lo sigue haciendo desde una perspectiva económica. Esto queda patente en el tercer principio (LOE, preámbulo, párrafo 22) en el que se inspira y que se refiere al tema del establecimiento de unos objetivos educativos comunes en el espacio europeo.

Esta ley, aunque introduce en su declaración de principios y fines valores de respeto, solidaridad, responsabilidad, equidad, justicia y democracia sigue organizándose a partir de la matriz patriarcal. Es urgente que la educación facilite la trascendencia de la misma y facilite la emergencia de una nueva matriz que incorpore la visión compleja de lo que significa ser humano.

El amor nos da seguridad, nos ayuda crecer sin miedo. Para poder avanzar hacia una educación que orbite también alrededor del amor y de la compasión necesitamos profesionales que asuman estas perspectivas. Si no cambian las mentalidades y los corazones de aquellos y aquellas que tienen que facilitar los procesos de aprendizaje integral, no cambiarán las prácticas. Ya sabemos que los cambios no se producen por decreto. Introducir estas perspectivas requiere la formación de profesionales que la faciliten y esto requiere también cambios en los paradigmas sobre los que se organiza el conocimiento sobre la formación docente inicial y permanente. También implica cambios en la selección de los y las docentes que se tienen que enfrentar con las nuevas formas de educar y formar a los futuros ciudadanos y ciudadanas del siglo XXI. Para ser un buen docente se requiere además de las competencias tradicionales basadas en el saber y el hacer, las basadas en el sentir pues su responsabilidad es facilitar, promover y conseguir el desarrollo máximo de todas las potencialidades de que dispongan sus alumnos y alumnas. 
Pero no sólo se educa en la escuela, hoy ya no es posible pensar en una escuela apartada de su entorno en la que no participen todos los miembros de la sociedad a la que pertenece. La participación de las familias, que debe implicar también formación para todos sus miembros, es indispensable. Y el entorno, un entorno ya sin límites que no puede entenderse de forma aislada, un entorno que forma parte de un mundo que cada vez es más pequeño y limitado, al que estamos irremediablemente unidos y que nos influye aun sin que queramos.

Sería algo así como cerrar el círculo si pensáramos que ante la complejidad del mundo que nos ha tocado vivir, ante las dificultades con las que nos encontramos, ante la rapidez de los cambios y la completa incertidumbre en la que vivimos sea necesario repensar la educación como un trabajo que ha de hacerse desde todos los ámbitos, educamos también cuando creemos que no lo hacemos, los niños y las niñas, los adolescentes, los jóvenes, todos ellos aprenden más de lo que nos ven hacer que de lo que les decimos que deben hacer. Si lo que respiran es amor, crecerán sin miedo.

\section{BiBLIOGRAFÍA}

Aguado, L. (2005) Emoción, afecto y motivación. Madrid, Alianza.

AlBORCH, C. (2002) Solas. Madrid, Aguilar.

Amorós, C. (1997) Tiempo de feminismo. Sobre feminismo, proyecto ilustrado y postmodernidad. Madrid, Cátedra.

CASTELLS, M. (1997) La era de la información. Economía, sociedad y cultura. Vol. 2. El poder de la identidad. Madrid, Alianza.

Dowling, C. (1989) Mujeres perfectas: el miedo a la propia incapacidad y cómo superarlo. Barcelona, Grijalbo.

EIsLER, R. (2001) La transformación social y lo Femenino: de la dominación a la colaboración solidaria, en ZWEIG, C. (ed.). Ser mujer. Barcelona, Kairós, 53-72.

FREIRE, P. y MACEDO, D. (1989) Alfabetización. Lectura de la palabra y lectura de la realidad. Barcelona, Paidós y MEC.

GidDens, G. (1991) Modernity and Self-Identity. Self and Society in the Late Modern Age. Oxford, Polity-Press.

Gilligan, C. (1982) In a Different Voice. Psicological Theory and Woman's Development. Harvard, University Press.

GonzÁlez de ChÁveZ, A. (ed.) (1999) Subjetividad y ciclos vitales de las mujeres. Madrid, Siglo XXI.

HALl, J. y JACOBS, R. (1994) La mujer sabia: Vivir la menopausia con plenitud. Madrid, Gaia.

HANCOCK, E. (2001) La niña interior: piedra de toque de la identidad femenina, en ZweIG, C. (ed.). Ser mujer. Barcelona, Kairós, 97-113.

Hirigoyen, M. (1999) El acoso moral: El maltrato psicológico en la vida cotidiana. Barcelona, Paidós.

LAGARDE, M. (1996) Género y feminismo. Desarrollo bumano y democracia. Madrid, Horas y Horas.

- (2000) Claves feministas para la autoestima de las mujeres. Madrid, Horas y Horas.

LEDoux, J. (1999) El cerebro emocional. Barcelona, Ariel-Planeta.

(c) Ediciones Universidad de Salamanca

Teor. educ. 18, 2006, pp. 175-200 
Lomas, C. (comp.) (2003) ¿Todos los hombres son iguales? Identidades Masculinas y cambios sociales. Barcelona, Paidós.

Maturana, H. (2003) Desde la biología a la psicología. Buenos Aires, Lumen.

MorIn, E. (1984) Ciencia con conciencia. Barcelona, Anthropos.

- (1998) Introducción al pensamiento complejo. Barcelona, Gedisa.

- (2001) Los siete saberes necesarios para la educación del futuro. Barcelona, Paidós.

NARANJo, C. (2004) Cambiar la educación para cambiar el mundo. Vitoria-Gasteiz, La Llave.

Rojas, L. (2004) Nuestra incierta vida normal. Madrid, Aguilar.

SALOMON, P. (2003) La mujer solar. El final de la guerra de los sexos. Barcelona, Obelisco.

- (2005) Los bombres se transforman. El hombre lunar. Barcelona, Obelisco.

SCHIERSE, L. (2005) La mujer herida. Cómo sanar la relación padre-bija. Barcelona, Obelisco.

SERVAN, D. (2003) Curación emocional. Acabar con el estrés, la ansiedad y la depresión sin fármacos ni psicoanálisis. Barcelona, Kairós.

SHLAIN, L. (2000) El alfabeto contra la diosa. El conflicto entre la palabra y la imagen, el poder masculino y el poder femenino. Madrid, Debate.

Taylor, S. E.; Klein, L. C.; Lewis, B. P.; Gruenewald, T. L.; Gurung, R. A. R. y UpdegrafF, J. A. (2000) Female Responses to Stress: Tend and Befriend, Not Fight or Flight, Psychological Review, 107 (3), 414-429.

VALCÁrCEL, A. (1993) Del miedo a la Igualdad. Barcelona, Crítica.

VARELA, P. (2002) Ansiosa-Mente. Claves para conocer y desafiar la ansiedad. Madrid, La Esfera-Libros.

WaLton, S. (2005) Humanidad. Una historia de las emociones. Madrid, Taurus.

WILBER, K. (1985) La conciencia sin fronteras. Aproximaciones de Oriente y Occidente al crecimiento personal. Barcelona, Kairós.

- (1996) Sexo, ecología y espiritualidad. El alma de la evolución, vol. 1. Madrid, Gaia.

- (2001) Una teoría de todo. Barcelona, Kairós.

ZeLDIN, T. (1996) Historia intima de la bumanidad. Madrid, Alianza.

ZWEIG, C. (ed.) (2001) Ser mujer. Barcelona, Kairós. 